\title{
The calculation of anchors in steel-concrete overlaps with precast slab
}

\author{
Alexander Tusnin and Alexey Kolyago ${ }^{*}$ \\ Moscow State University of Civil Engineering, Yaroslavskoe shosse, 26, Moscow, 129337, Russia
}

\begin{abstract}
Reinforced concrete floors and steel beams are widely used in buildings and structures for various purposes. Reinforced concrete overlaps can be cast-in or precast of hollow-core slabs. The most effective floors in which the concrete slab is located in the compressed area of cross-section, in steel beams in the tension zone, and shifting forces, arising between concrete slab and the steel beam, are perceived by anchors. Precast slabs in comparison with cast-in ones have less labor-intensive performance, the beam spacing is equal to the span of reinforced concrete slabs, there are no intermediate beams in such overlaps, that allows to reduce the floor thickness. The inclusion of precast in steel-concrete cross-section requires joints with steel beams, which requires using of special anchors. Anchor perceives shear forces and ensures the joint operation of the plate and the steel beam. In addition, for beams with narrow flange, the anchor device can provide the required width of the support slabs. The calculation of the attachment points of the anchors to the steel beam is carried out using three variants of calculation methods, which allow to determine the forces acting on the anchor. For practical application, a wire-element model has been proposed and managed to get forces in a steel beam, slab and anchors the width of the slab recommended by the standards should be included in the calculation model.
\end{abstract}

\section{Introduction}

The behavior of the composite structure differs from the behavior of steel or reinforced concrete construction due to the presence of shear anchors[1]. In cast-in overlaps anchors are made of stud bolts, that are welded to the upper flange of a steel beam. After maturing by concrete a steel-concrete structure is formed. The researches of the construction of a cast-in slab and anchors in the form of stud-bolts were conducted by many authors. Experimental studies are performed on full-scale structures or prototype models. Numerical calculations of composite structures are carried out by the finite-element method in linear and nonlinear formulation. The calculation of the composite structure with anchors in the form of stud-bolts and its tests are considered in [2, 3, 4, 5]. The calculation of connection of the slab with a steel beam in the form of stud bolts in case of fire and constructive measures to improve their fire resistance are considered in [6]. The results of numerical

\footnotetext{
* Corresponding author: alex777002@gmail.com
} 
calculations of stud bolts work are presented in [7, 8, 9]. The effect of low temperatures on anchors in the form of stud bolts was studied in [10]. The effect of concrete shrinkage on structural behavior depending on shear stiffness joint was considered in [11]. The effect of long-term load on the overlaps in the area of anchors was investigated in [12].

Futher, for joining reinforced concrete slabs anchors in the form of bolts [13], angles, Ibeams and channels $[14,15]$ are used. To connect a reinforced concrete slab with a steel beam are also used inclined and vertical supports made of reinforcing bars with a bend at the end. Longitudinal reinforcement of cast-in slabs, which can be attached to the steel beam and rigid anchors [16].

During constructing overlaps by using precast concrete slabs, the design of anchor should be chosen taking into account the required width of the slabs bearing on the beam. For precast hollow core slabs with a span of $6 \mathrm{~m}$ or more, the width of the bearing on steel beams is $70-90 \mathrm{~mm}$. With a small width of the upper flange of the beam, it is not always possible to place stud bolts between the ends of the plates and it is more rationally arrange the anchors in the joints of the plates, which not only include in the joint work with the beam, but also provide the required width of slab bearing on the beam (figure 1).
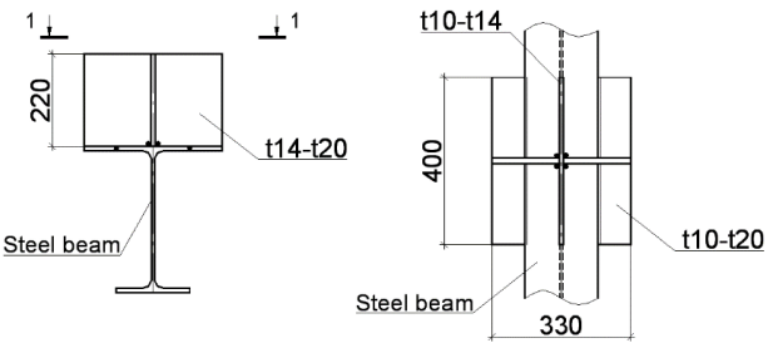

Fig. 1(a). Design of anchor and precast slab joints with steel beam. Anchor
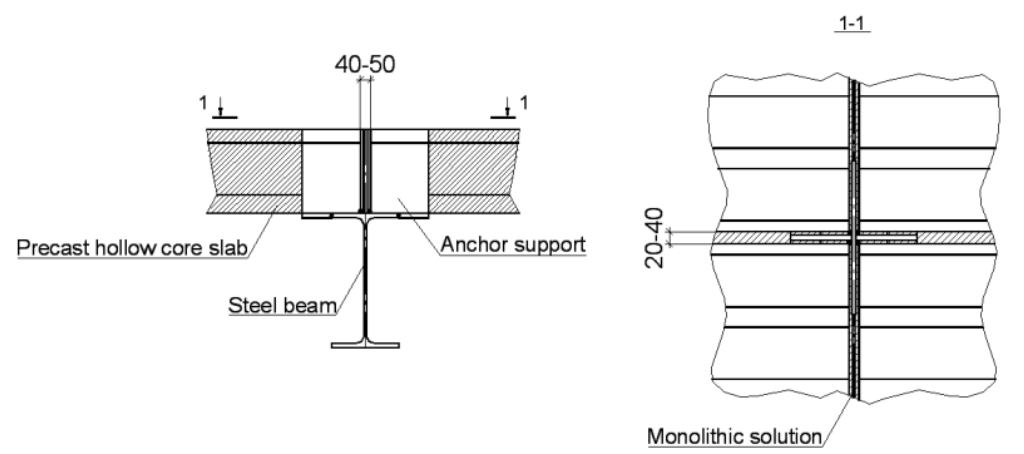

Fig. 1 (b). Design of anchor and precast slab joints with steel beam. Joints of slabs

\section{Calculation of anchors}

The calculation of composite structures in Russia is carried out in accordance with current rules [17, 18, 19]. In Europe, the design and calculation of composite structures is also standardized $[20,21]$. The calculation of composite elements in the indicated rules is based on the plane-section hypothesis. The bearing capacity according to rules is determined from the condition of reaching the yield strength in the stretched and compressed part of the steel beam; in this case the stresses in concrete are equal to the calculated concrete resistance to compression. Concrete in the stretched zone is excluded from consideration, and the stresses in the reinforcement of this zone are equal to the calculated resistance of the 
reinforcement. Rules provide recommendations for determining the position of the neutral axis of an aggregate reinforced concrete element.

To calculate the reinforced concrete elements, it is required to know the width of the reinforced concrete slab included in the work. Standards give recommendations on the appointment of the width of the plate and the calculation of the anchors. However, for hollow slabs to apply these recommendations is difficult. There are no recommendations in the norms on the determination of the forces on the anchor, when placing them along the beam only in the transverse joints of the plates.

\subsection{Defining of forces on anchors}

Anchors located closer to the support are more loaded. It should be noted that composite action of reinforced concrete slabs and steel beams is not necessary throughout the beam, but on the part of the span where the strength of the steel beam is not enough to perceive the load acting on the structure. The forces perceived by the extreme anchor stops, which are installed only in the transverse joints of precast slabs, can be calculated in different ways.

For an extreme anchor that interacts with one plate, the force $\mathrm{N}$ acting on the anchor can be determined using a well-known theoretical relationship [22]:

$$
N=M S / I
$$

In this expression $\mathrm{M}$ is the bending moment, $\mathrm{S}$ is the static moment of cut-off part of section (slab), I is the moment of inertia of the cross-section. Geometric characteristics are determined for the reduced section, which includes a steel I-beam and a precast slab (figure 2).

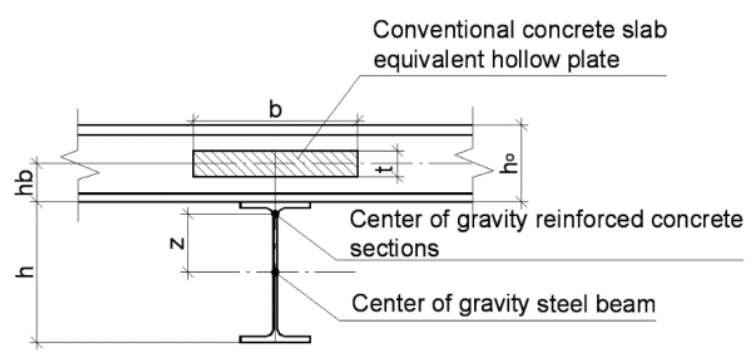

Fig 2. Steel-concrete cross-section for calculation.

Neutral axis of steel-concrete beam cross-section.

$$
z=\frac{k b t\left(h_{b}+\frac{h}{2}\right)}{k b t+A_{s t}} \text {, where } k=\frac{1}{\alpha_{b}}=\frac{E_{b}}{E_{s t}} \text { is relation of Poison`s ratios of concrete and }
$$

steel, $A_{s t}$ - cross-section area of I-beam.

Moment of inertia of the cross-section steel-concrete beam: $I=I_{s t}+A_{s t} z^{2}+k b t\left(h_{b}+h / 2-z\right)^{2}+k b t^{3} / 12$.

Static moment of slab over the neutral axis of steel-concrete cross-section: $S=k b t\left(h_{b}+h / 2-z\right)$. 


\subsection{Defining of stresses in precast slabs}

The specified parameters are determined in the section where the first anchor is located. The peculiarity of using equation (1) is that at the installation site of the first anchor, the cross section changes strongly - it is converted from a steel I-beam into a steel-concrete cross-section, consisting of a steel beam and a reinforced concrete slab. The new section has much more moment of inertia, the neutral axis moves to the upper zone of the beam. Section varies in the area of the anchor spasmodically. The equation (1) derived for a bendable element with the moment of inertia unchanged along the structure and the position of the neutral axis for the composite concrete structure can be applied with certain restrictions.

Before the first anchor the beam works as usual, after the anchor the beam and hollow-core slabs work together. To determine force on the first anchor stop, we can use the method of calculating the self-stress in tightening the prestressed steel beam [23]. In the reinforced concrete structure, instead of the stretched tension a compressed slab is considered. Figure 3 shows the design diagram of the steel-concrete structure, while $e=h / 2+h_{b}$.

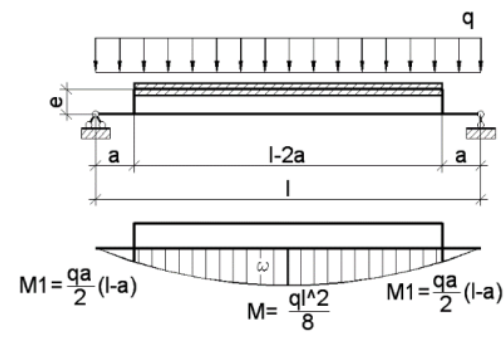

Fig. 3. Structural analyses scheme of steel-concrete construction with 2 anchors

Force in the slab is determined by the equation:

$$
N=\frac{M_{1} \omega}{I_{s t}\left(\frac{M_{1}^{2}}{I_{s t}}+\frac{1}{k A_{b}}+\frac{1}{A_{s t}}\right)(l-2 a)}
$$

In the expression (2) $M_{1}=1 \cdot e=e, \omega$ is area of bending moment diagram, $A_{b}$ is plate area.

With a uniformly distributed load force in slab and on anchors of steel concrete structure is:

$$
N=\frac{e q\left(a(l-a)+\frac{l^{2}}{2}\right)}{6 I_{s t}\left(\frac{e^{2}}{I_{s t}}+\frac{1}{k A_{b}}+\frac{1}{A_{s t}}\right)}
$$

The same effort can be obtained by calculating the wire-elements model using the finite element analyses. Table 1 presents the results of calculating the forces on the anchor support using equation 1, and table 2 using equation 3. Calculations are made for beams with a span of 6 and 12 m loaded with a distributed load of $48.77 \mathrm{kN} / \mathrm{m}$. The steel beam is made of rolling I-beams at STO ASCHM 20-93 25B2 (span of $6 \mathrm{~m}$ ) and 40B2 (span of 12 $\mathrm{m})$. The reinforced concrete slab with a thickness of $220 \mathrm{~mm}$ is made of B20 concrete class, design resistance of concrete is $11.5 \mathrm{MPa}$, the modulus of elasticity is $27500 \mathrm{MPa}$. To calculate the equivalent thickness of the slab is assumed to be equal to the sum of the thicknesses of the lower and upper walls of the voids in the slab of $83 \mathrm{~mm}$, the width of the 
slab is $330 \mathrm{~mm}$, the slab works only for compression without bending. For a beam with a span of $6 \mathrm{~m}$, the location of the anchors at a distance of 0.6 and $1.5 \mathrm{~m}$ from the support is considered, for a beam with a span of $12 \mathrm{~m}-1.2$ and $3.0 \mathrm{~m}$.

Table 1. Force on anchor, defining by equation 1

\begin{tabular}{|l|c|c|c|c|}
\hline & \multicolumn{2}{|c|}{ Beam 6 m span } & \multicolumn{2}{c|}{ Beam 12 m span } \\
\hline Distance from anchor to support & 0.6 & 1.5 & 1.2 & 3.0 \\
\hline Force on anchor $(\mathrm{kN})$ & 237.4 & 494.7 & 602.3 & 1161.1 \\
\hline
\end{tabular}

Table 2. Force on anchor, defining by equation 3

\begin{tabular}{|l|c|c|c|c|}
\hline & \multicolumn{2}{|c|}{ Beam 6 m span } & \multicolumn{2}{c|}{ Beam 12 m span } \\
\hline Distance from anchor to support & 0.6 & 1.5 & 1.2 & 3.0 \\
\hline Force on anchor $(\mathrm{kN})$ & 486.3 & 529.8 & 1045.7 & 1139.2 \\
\hline
\end{tabular}

\section{Finite element analyses of steel-concrete cross-section}

Results obtained by different methods were compared with results of core model calculation by the Lira-SAPR 2012 software. Wires that modeling the beam and the slab were taken with corresponding stiffness characteristics. A high rigidity wires modeled the anchors. Table 3 compares results of determining force on the anchors. In addition to the values of the efforts Table 3 shows errors with respect to efforts obtained by using the FEM.

Table 3. Comparison of forces on anchor

\begin{tabular}{|c|c|c|c|c|c|c|c|}
\hline \multirow{2}{*}{$\begin{array}{c}\text { Span } \\
(\mathbf{m})\end{array}$} & \multirow{2}{*}{$\begin{array}{c}\text { Anchor } \\
\text { location, } \mathbf{m}\end{array}$} & \multicolumn{2}{|c|}{ Equation 1 } & \multicolumn{2}{c|}{ Equation 3 } & \multicolumn{2}{|c|}{ FEM } \\
\cline { 3 - 8 } & $\mathbf{N}(\mathbf{k N})$ & $\mathbf{d}(\boldsymbol{\%})$ & $\mathbf{N}(\mathbf{k N})$ & $\mathbf{d}(\boldsymbol{\%})$ & $\mathbf{N}(\mathbf{k N})$ & $\mathbf{d}(\%)$ \\
\hline \multirow{2}{*}{6} & 0.6 & 237.4 & -54 & 486.3 & -6 & 518.1 & 0 \\
\cline { 2 - 8 } & 1.5 & 494.7 & -18 & 529.8 & -13 & 605.8 & 0 \\
\hline \multirow{2}{*}{12} & 1.2 & 602.3 & -35 & 1045.7 & 13 & 924.5 & 0 \\
\cline { 2 - 8 } & 3.0 & 1161.1 & 8 & 1139.2 & 6 & 1078.0 & 0 \\
\hline
\end{tabular}

Difference of efforts obtained by using the equation 2 and the FEM does not exceed $13 \%$. Equation 1 gives significant (up to 54\%) error. Taking into account the analysis carried out for calculating forces on anchor supports we can recommend either equation 2 or the FEM. For practical use it is rational to use the FEM like most multipurpose.

By the far from the anchor along beam part of the slab, increasing width, joins with the steel profile. The width of the slab varies from the width of the anchor support base plate $(330 \mathrm{~mm})$ to $1 / 6$ of span of the beam in each direction from axis of the beam. With $6 \mathrm{~m}$ beam span the slab width reaches $2 \mathrm{~m}$ and with a span of $12 \mathrm{~m}-4 \mathrm{~m}$.

Figure 4 shows dependence between force on the anchor stop equal to force in the slab, for a beam with $6 \mathrm{~m}$ span, in figure 5 - the same for a beam with $12 \mathrm{~m}$ span. 


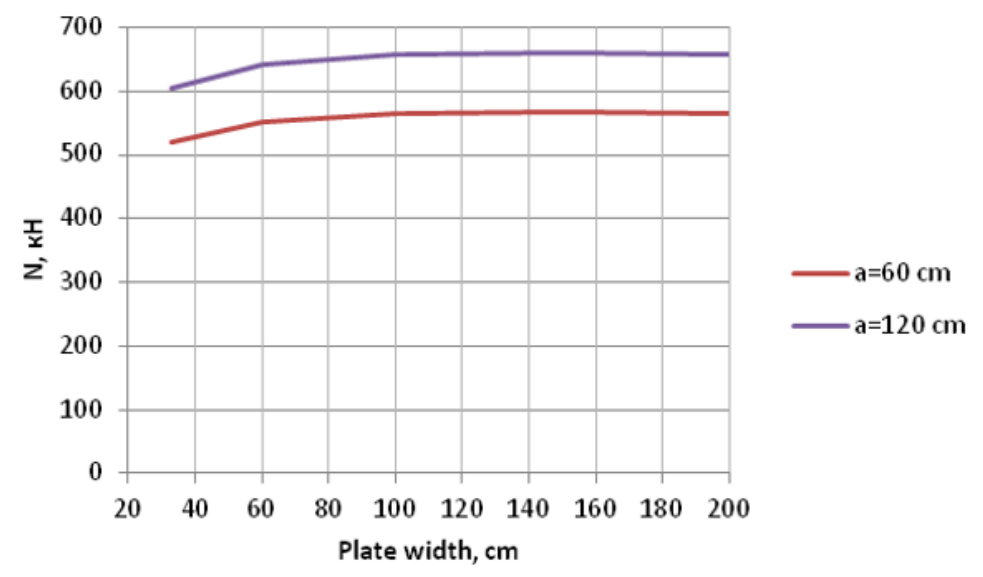

Fig. 4. Dependence of force on anchor for beam $6 \mathrm{~m}$ span

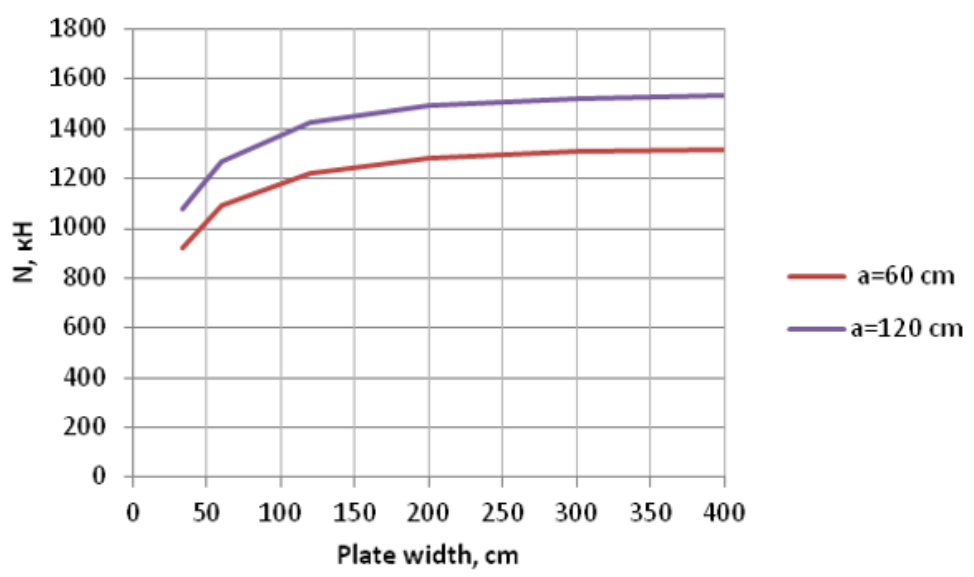

Fig. 5. Dependence of force on anchor for beam $12 \mathrm{~m}$ span

\subsection{Parameters and calculation models of steel-concrete beam}

The calculations have revealed the following. For a beam with $6 \mathrm{~m}$ span increase in width of the slab from 33 to $200 \mathrm{~cm}$ (6.1 times) leads to increase in strength in the slab of $9 \%$; for a beam with $12 \mathrm{~m}$ span increase in width from $33 \mathrm{~cm}$ to $400 \mathrm{~cm}$ (12.1 times) lead to increase force in slab of $43 \%$. The main force increase for a beam spanning $6 \mathrm{~m}$ occurs when the slab width increases from $33 \mathrm{~cm}$ to $60 \mathrm{~cm}$, and for a beam spanning $12 \mathrm{~m}$ when the slab width increases from $33 \mathrm{~cm}$ to $120 \mathrm{~cm}$.

Wires that modeling the slab can be made with a cross section of variable width along length of the beam. The width of wires replacing the slab is defined in Table 4. To determinate width of wires' section is taken increase in width with distance from point of load application at 45 degrees angle. Section width of three wires changed from support, the other wires had $200 \mathrm{~cm}$ width (span $6 \mathrm{~m})$ and $400 \mathrm{~cm}$ (span $12 \mathrm{~m})$. 
Table 4. Width of wires cross-section.

\begin{tabular}{|l|c|c|}
\hline \multirow{2}{*}{\multicolumn{1}{|c|}{ Cross-section }} & \multicolumn{2}{c|}{ Cross-section width (cm) } \\
\cline { 2 - 3 } & Span 6 m & Span 12 m \\
\hline Width of anchor & 33 & 33 \\
\hline Width in middle of span & 200 & 400 \\
\hline First wire from anchor & 63 & 93 \\
\hline Second wire from anchor & 123 & 213 \\
\hline Thirst wire from anchor & 183 & 333 \\
\hline Other wires & 200 & 400 \\
\hline
\end{tabular}

\subsection{Comparison of calculations results}

Table 5 presents the FEM calculation results for the following options:

- model 1 with wires modeling the slab with $200 \mathrm{~cm}$ constant width with $6 \mathrm{~m}$ span and $400 \mathrm{~cm}$ with $12 \mathrm{~m}$ span;

- $\quad$ model 2 with wires, modeling slab of variable width;

- model 3 with wires simulating slab of constant width equal to averaged values: $(33+$ 200) $/ 2=116.5 \mathrm{~cm}$ with $6 \mathrm{~m}$ span, $(33+400) / 2=216.5 \mathrm{~cm}$ with $12 \mathrm{~m}$ spa.

Table 5. Forces on anchors and bending moments in steel beams in wire-element models

\begin{tabular}{|c|c|c|c|c|c|c|c|c|}
\hline \multirow{3}{*}{$\begin{array}{l}\text { Cross- } \\
\text { section }\end{array}$} & \multicolumn{4}{|c|}{ Span $6 \mathrm{~m}$} & \multicolumn{4}{|c|}{ Span $12 \mathrm{~m}$} \\
\hline & \multicolumn{2}{|c|}{$\mathrm{a}=0.6 \mathrm{M}$} & \multicolumn{2}{|c|}{$\mathrm{a}=1.5 \mathrm{M}$} & \multicolumn{2}{|c|}{$\mathrm{a}=1.2 \mathrm{M}$} & \multicolumn{2}{|c|}{$\mathbf{a}=\mathbf{3 . 0}$ м } \\
\hline & $\mathrm{N}(\mathrm{kN})$ & $\mathrm{d}(\%)$ & $\mathrm{N}(\mathrm{kN})$ & $\mathrm{d}(\%)$ & $\mathrm{N}(\mathrm{kN})$ & $\mathrm{d}(\%)$ & $\mathrm{N}(\mathrm{kN})$ & $\mathrm{d}(\%)$ \\
\hline Model 1 & 598.3 & $0.0 \%$ & 697.2 & 0.0 & 1651 & 0.0 & 1924 & 0.0 \\
\hline Model 2 & 592.2 & $1.0 \%$ & 685.9 & 1.6 & 1615 & 2.2 & 1857 & 3.5 \\
\hline Model 3 & 586.9 & $1.9 \%$ & 683.9 & 1.9 & 1596 & 3.3 & 1859 & 3.4 \\
\hline & $\begin{array}{c}\mathrm{M} \\
(\mathrm{kN} \mathrm{m})\end{array}$ & $\mathrm{d}(\%)$ & $\begin{array}{c}\mathrm{M} \\
(\mathrm{kN} \mathrm{m})\end{array}$ & $\mathrm{d}(\%)$ & $\begin{array}{c}\mathrm{M} \\
(\mathrm{kN} \mathrm{m})\end{array}$ & $\mathrm{d}(\%)$ & $\begin{array}{c}\mathrm{M} \\
(\mathrm{kN} \mathrm{m})\end{array}$ & $\mathrm{d}(\%)$ \\
\hline Model 1 & 78.87 & $0.0 \%$ & 55.63 & 0.0 & 365.9 & 0.0 & 281.3 & 0.0 \\
\hline Model 2 & 80.29 & $1.8 \%$ & 58.27 & 4.7 & 377.2 & 3.1 & 302.1 & 7.4 \\
\hline Model 3 & 81.53 & $3.4 \%$ & 58.74 & 5.6 & 383.2 & 4.7 & 301.9 & 7.3 \\
\hline
\end{tabular}

The forces on anchor in examined models are not significantly dependent on cross-section width of wires modeling the slab. The bending moments in steel beam with variable or averaged width of wires that modeling the slab are slightly larger than in models with section width of these wires, passed in standards. Taking into account obtained results it appears that simple wire model can be used to calculate forces in steel-concrete structure.

The wire-elements model is used in calculation of structures with $6 \mathrm{~m}$ and $12 \mathrm{~m}$ span with fastening of reinforced concrete slab to steel beam in several places. With $6 \mathrm{~m}$ span there 
are 8 plates $1200 \mathrm{~mm}$ wide that installed on beam and 5 anchor supports that used in joints between plates, two extreme supports are situated at the $600 \mathrm{~mm}$ distance from the beam. With $12 \mathrm{~m}$ span there are 18 plates $1200 \mathrm{~mm}$ wide that are laid on beam and 10 anchor supports that are used in joints between plates, two extreme supports are at the $600 \mathrm{~mm}$ distance from the beam. The behavior of wire-elements models with constant width of wire sections replacing a slab, as well as with variable width in accordance with Table 4 is considered. Tables $6-8$ present forces in the beam model. Efforts obtained by calculating various models were compared with efforts in the model with different slab's width.

Table 6. Forces on anchors in wire-element models, including several anchors

\begin{tabular}{|l|c|c|c|c|}
\hline \multirow{2}{*}{ Cross-section } & \multicolumn{2}{|c|}{ Span 6 m } & \multicolumn{2}{c|}{ Span 12 m } \\
\cline { 2 - 5 } & $\mathbf{N}(\mathbf{k H})$ & $\mathbf{d}(\%)$ & $\mathbf{N}(\mathbf{k H})$ & $\mathbf{d}(\%)$ \\
\hline Model 1 & 493.4 & 0.0 & 732.1 & 0.0 \\
\hline Model 2 & 486.3 & 1.4 & 679.5 & 7.2 \\
\hline Model 3 & 495.5 & 0.4 & 713.9 & 2.5 \\
\hline
\end{tabular}

Table 7. Longitudal forces in span in wire-element models, including several anchors

\begin{tabular}{|l|c|c|c|c|}
\hline \multirow{2}{*}{ Cross-section } & \multicolumn{2}{|c|}{ Span 6 m } & \multicolumn{2}{c|}{ Span 12 m } \\
\cline { 2 - 5 } & $\mathbf{N}(\mathbf{k H})$ & $\mathbf{d}(\%)$ & $\mathbf{N}(\mathbf{k H})$ & $\mathbf{d}(\%)$ \\
\hline Model 1 & 709.7 & 0.0 & 2059 & 0.0 \\
\hline Model 2 & 711.1 & 0.2 & 2058 & 0.0 \\
\hline Model 3 & 707.7 & 0.3 & 2002 & 2.8 \\
\hline
\end{tabular}

Table 8. Bending moments of steel beam in span in wire-element models, including several anchors

\begin{tabular}{|l|c|c|c|c|}
\hline \multirow{2}{*}{ Cross-section } & \multicolumn{2}{|c|}{ Span 6 m } & \multicolumn{2}{c|}{ Span 12 m } \\
\cline { 2 - 5 } & M (kH M) & d (\%) & M (kH M) & d (\%) \\
\hline Model 1 & 52.67 & 0.0 & 239.8 & 0.0 \\
\hline Model 2 & 52.37 & 1.5 & 239.8 & 6.8 \\
\hline Model 3 & 53.16 & 0.9 & 257.3 & 7.3 \\
\hline
\end{tabular}

Obtained forces can be used to calculate the steel beam, precast slab and anchors structural design. Precast reinforced concrete slabs are encouraged to be replaced with wires of averaged width (model 2 ) or variable width (model 3 ).

For the structure with $6 \mathrm{~m}$ span, including 4 plates $1200 \mathrm{~mm}$ wide with three anchor supports, the normal stresses in the lower and upper flanges of I-beam are determined. Results are obtained by calculating the simple wire-elements model and the spatial finite 
element model (table 9). To use wire-elements models the cross-section thickness of wires simulating the slab is assumed to be $83 \mathrm{~mm}$ (total thickness of casings) or thickness of the upper plating - $22.5 \mathrm{~mm}$.

Table 9. Normal stresses of steel beam $6 \mathrm{~m}$ span in wire-element models, including several anchors

\begin{tabular}{|c|c|c|c|c|c|}
\hline \multirow{2}{*}{ Cross-section } & \multirow{2}{*}{$\begin{array}{l}\text { Displacements } \\
\quad(\mathrm{mm})\end{array}$} & \multicolumn{2}{|c|}{ Forces } & \multicolumn{2}{|c|}{$\operatorname{Stresses}\left(\mathbf{k N} / \mathbf{c m}^{2}\right)$} \\
\hline & & $\mathbf{N}(\mathbf{k N})$ & $M(\mathbf{k N} \cdot \mathbf{m})$ & $\begin{array}{c}\text { Bottom } \\
\text { flange }\end{array}$ & $\begin{array}{c}\text { Top } \\
\text { flange }\end{array}$ \\
\hline \multicolumn{6}{|c|}{ Slabs width $83 \mathrm{~mm}$} \\
\hline Model 1 & 19.7 & 709.7 & 52.67 & 35.1 & 2.6 \\
\hline Model 2 & 20.2 & 711.1 & 52.37 & 35.0 & 2.7 \\
\hline Model 3 & 21.5 & 707.7 & 53.16 & 35.2 & 2.4 \\
\hline \multicolumn{6}{|c|}{ Slabs width $22.5 \mathrm{~mm}$} \\
\hline Model 1 & 16.2 & 538.5 & 44.56 & 28.0 & 0.6 \\
\hline Model 2 & 17.1 & 539.3 & 43.65 & 27.8 & 0.9 \\
\hline Model 3 & 19.1 & 519.2 & 51.07 & 29.5 & -2.0 \\
\hline
\end{tabular}

To use wires $83 \mathrm{~mm}$ thick it is assumed that the lower common surface of plate is compressed. However, on the basis of calculation, tensile stresses arise in the lower shell, which leads to its exclusion from design, therefore, was calculated the model which included only upper shell with $22.5 \mathrm{~mm}$ thick. Based on the calculation carried out by modeling only the upper shell for models 1 and 2, the lower shell is stretched, for model 3 the lower shell is compressed.

The comparison of numerical calculation results of $6 \mathrm{~m}$ span beam was implemented, with 8 hollow-core slabs, with results of calculation this steel-reinforced concrete structure according to the current standards [18]. To carry out calculations by standards width of plate is $2 \mathrm{~m}$. Two options for inclusion of plate into compression work are considered:

upper and lower shells are compressed;

lower shell is stretched, upper shell is compressed.

Results of calculations by standards shown in table 10 .

Table 10. Calculations results of steel-concrete beam by standards.

\begin{tabular}{|l|c|c|}
\hline \multicolumn{1}{|c|}{ Parameter } & Both shell included & Only top shell included \\
\hline Stresses in bottom shell $\left(\mathrm{kN} / \mathrm{cm}^{2}\right)$ & 0.25 & - \\
\hline Stresses in top shell $\left(\mathrm{kN} / \mathrm{cm}^{2}\right)$ & -1.47 & -1.26 \\
\hline Stresses in bottom flange $\left(\mathrm{kN} / \mathrm{cm}^{2}\right)$ & 30.25 & 28.16 \\
\hline Stresses in top flange $\left(\mathrm{kN} / \mathrm{cm}^{2}\right)$ & -8.76 & -0.68 \\
\hline
\end{tabular}

Comparison of calculation results of wire-elements model with standard calculation showed that maximum stresses in lower flange of steel beam when only upper shell was put into work, obtained in different ways, do not vary more than 5\%. Assuming that both shells of slab are put into work, the difference in stresses obtained by two methods reaches $16 \%$. 


\section{Conclusion}

The use of precast reinforced concrete slabs, working with steel beams, ensures the implementation of fully-precast overlaps in multi-story buildings with steel frame. For joints prefabricated slabs are proposed anchor, which ensure work of slabs and beams and increase support area of slabs on the beam. The wire-elements model is proposed that allowed calculating forces in steel beam, plate and anchor supports. The research of composite structure behavior showed that slab width recommended by standards should be included in calculation model. The thickness of slab is set taking into account the sign of stresses arising in reinforced concrete slab. The difference between the calculation using the wire-elements model and the calculation according to the current standards is $5-16 \%$.

\section{References}

1. Chung L, Lim J, Hwang H, E 2016 Review of Design Flexural Strengths of SteelConcrete Composite Beams for Building Structures International Journal of Concrete Structures and Materials 10 109-121.

2. Szewczyk P and Szumigala M 2015 Numerical modelling of the strengthening process of steel-concrete composite beams Civil and environmental engineering reports 1999 110.

3. Anju T and Smitha K K Finite Element Analysis of Composite Beam with Shear Connectors Procedia Technology 24179 - 187.

4. Lawson R M, Lam D, Aggelopoulos E S and Nellinger S 2017 Serviceability performance of steel-concrete composite beams Proceedings of the Institution of Civil Engineers 98 - 114.

5. Lam D, Dai X, Ashou, Ashraf F and Rehman N 2017 Recent research on composite beams with demountable shear connectors Steel Construction: Design and Research 10(2) $125-134$.

6. Yisel L, Rafael L and Valdir P S Design of stud connections in steel - concrete composite structures in fire situation Revista ingenieria de construccion $3039-52$.

7. Jorge B, Luciano M B, Rafael L, Carlos R and Enrique M Numerical modelling with experimental validation applied to the study of stud connectors behaviour in concrete and steel composite structures Revista ingenieria de construccion $3053-68$.

8. Lin J P, Wang J F and Xu R Q. 2014 Cohesive Zone Model Based Numerical Analysis of Steel-Concrete Composite Structure Push-Out Tests Mathematical Problems in Engineering 12.

9. Bouchair A, Bujnak J, Duratna P and Lachal A. Modeling of the Steel-Concrete PushOut Test Procedia Engineering $40102-107$.

10. Wenqi H, Meixin Y and Yezhi Z 2011 Cryogenic fatigue behaviour of steel-concrete composite structures 9th International Conference on Damage Assessment of Structures (DAMAS 2011) Journal of Physics: Conference Series 305.

11. Bradford M A 2011On the Interaction of Partial Interaction and Shrinkage in Composite Steel-Concrete T-Beams Procedia Engineering 14396 - 401.

12. Bílý P, Fládr J, Kohoutková A 2017 Behavior of anchorage areas in the steel-concrete composite structure loaded by longitudinal shear forces // Procedia Engineering 172 $104-110$.

13. Ataei A, Bradford M A and Valipour H 2016 Sustainable Design of Deconstructable Steel-Concrete Composite Structures Procedia Engineering 1451153 - 1160.

14. Titoum M, Mazoz A, Benanane A and Ouinas D. Experimental study and finite element modelling of push-out tests on a new shear connector of i-shape Advanced Steel Construction $12487-506$. 
15. Kim S, Kim K, Lee D, Park J and Han O. Analysis of the Shear Behavior of Stubby YType Perfobond Rib Shear Connectors for a Composite Frame Structure Materials 2017 $101-109$.

16. Streletskiy N. 1965 Stalezhelezobetonnyye mosty 376.

17. SP 35.13330.2011. Mosty i truby. M.,2011. 340.

18. SP 266.1325800.2016. Konstruktsii stalezhelezobetonnyye. M.,2016. 134.

19.STO ARSS 11251254.001-018-4. Rukovodstvo po proyektirovaniyu stalezhelezobetonnykh konstruktsiy. M.,2018. 106.

20. EN 1994-1-1. Eurocode 4: Design of composite steel and concrete structures -Part 1-1: General rules and rules for buildings. 2004, 118.

21. EN 1994-2. Eurocode 4: Design of composite steel and concrete structures -Part 2: General rules and rules for bridges. 2005, 90.

22. Belyayev N. 1965 Soprotivleniye materialov 856.

23. Belenya E., Streletskiy N. 1991 Metallicheskiye konstruktsii. Spetsial'nyy kurs 684. 